\title{
Biophysiology of Oral Mucosal Melanocytes
}

\author{
Shilpa C Natesan ${ }^{1}$, Bindhu P Ramakrishnan ${ }^{2}$, Rekha Krishnapillai ${ }^{3}$, Priya Thomas ${ }^{4}$
}

\begin{abstract}
Melanocytes are specialized cells derived from the fourth germ layer-the neural crest cells. They play an important role in human pigmentation through their ability to produce melanin. In addition to skin, melanocytes are also seen in eyes, ear, adipose tissue, brain, heart, and oral mucosa. Although melanin production is the chief function, melanocytes located in various other parts of the body have different roles. These dendritic cells identified in the oral mucosa are very much similar to epidermal melanocytes. The information on oral mucosal melanocytes is mainly from the research conducted on epidermal melanocytes. Hence, the knowledge on the development, morphology, and functions of oral mucosal melanocytes is very much limited. Therefore, this review is to provide more insights into the biophysiological aspects of oral mucosal melanocytes. Keywords: Dendritic cells, Melanin, Melanocytes, Oral mucosal melanocytes, Pigmentation.

Journal of Health Sciences \& Research (2019): 10.5005/jp-journals-10042-1083
\end{abstract}

\section{INTRODUCTION}

The history of research in human pigmentation can be traced back to 2200 BC in the ancient literature of Iran. Only with the advent of microscope and stained sections in the 19th century, the discovery of melanocytes (MCs) was made possible. ${ }^{1}$

Melanocytes are a heterogeneous group of cells derived from the neural crest cells (NCCs). Their unique property of melanin production aids in the physiologic pigmentation of the skin. The primary habitats of MCs were believed to be the skin and hair follicles. However, it was later understood that MCs can also be found in oral mucosa, ear, eyes, heart, brain, and adipose tissue. Based on their habitat, MCs can be classified into cutaneous/ follicular and extracutaneous MCs. ${ }^{2}$ These extracutaneous MCs perform many extra-pigmentary functions that are still under speculation.

The presence of oral mucosal MCs (OMMCs) in gingiva was first identified by Laidlaw and Cahn in $1932 .{ }^{3}$ It is reported that they can be found in the oral tissues by the third month in utero. ${ }^{4}$ The majority of the information known to us about OMMCs are as a result of the studies conducted on epidermal melanocytes. Also, a literature search of OMMCs in Pubmed and Google Scholar yielded only a handful of articles that include minimal reviews. Therefore, this review article is primarily focused on compiling the current knowledge on the biophysiological aspects of MCs with special reference to OMMCs.

\section{History}

A brief history of the major discoveries in the field of MCs is given in Table $1{ }^{1,5}$

\section{Origin and Development}

Melanocytes are derived from NCCs that are embryonic derivatives of ectoderm. ${ }^{6,7}$ The NCCs are divided into cranial, vagal, trunk, and sacral according to their embryonic migratory pathways. Epidermal MCs present in the head region originate from the cranial NCCs, while those in the remaining parts of the human body are mainly from the trunk NCCs. Trunk NCCs are again divided into dorsolaterally and ventrally migrating cells. Majority of MCs originate from dorsolaterally migrating cells. However, it is stated ${ }_{1-4}^{1-4}$ epartment of Oral Pathology and Microbiology, Annoor Dental
College and Hospital, Muvattupuzha, Kerala, India

Corresponding Author: Shilpa C Natesan, Department of Oral Pathology and Microbiology, Annoor Dental College and Hospital, Muvattupuzha, Kerala, India, Phone: +91 9048605496, e-mail: sshilpacn@gmail.com

How to cite this article: Natesan SC, Ramakrishnan BP, Krishnapillai R, et al. Biophysiology of Oral Mucosal Melanocytes. J Health Sci Res 2019;10(2):47-51.

Source of support: Nil

Conflict of interest: None

that cells migrating ventrally either differentiate into neurons or are maintained as multipotent cells that differentiate into cells forming myelin sheath or melanocytes. ${ }^{8}$

The molecular interactions of several signaling pathways, transcription factors, and adhesion proteins act collectively for the specification of melanoblast lineage from neuronal lineage. The chief signaling pathways involved in the process are Wnt and BMP along with stem cell factor and its c-kit ligand. The Wnt signaling pathway promotes melanoblast differentiation, while BMP signaling

Table 1: Major discoveries in the field of melanocytes

\begin{tabular}{lll}
\hline Author & Year & Contribution \\
\hline Giosue Sangiovanni & 1819 & $\begin{array}{l}\text { First to describe pigment in human } \\
\text { cells. "Chromatophores" } \\
\text { Identified pigments in animals } \\
\text { "pigment melanique" }\end{array}$ \\
Retterer & 1873 & $\begin{array}{l}\text { Pigmentation in basal epidermal } \\
\text { cells of fetus }\end{array}$ \\
Meyerson & 1889 & $\begin{array}{l}\text { Coined the term melanocytes } \\
\text { Baker }\end{array}$ \\
Laidlaw and Cahn & 1927 & $\begin{array}{l}\text { Presence of dendritic cells in basal } \\
\text { stratum layer of oral epithelium } \\
\text { OMMCs identified in gingival } \\
\text { epithelium }\end{array}$ \\
Rawles & 1948 & $\begin{array}{l}\text { Neural crest cell origin of } \\
\text { melanocytes } \\
\text { Coined the term melanosomes }\end{array}$ \\
Seiji et al. & 1963 & \\
\hline
\end{tabular}

(-) The Author(s). 2019 Open Access This article is distributed under the terms of the Creative Commons Attribution 4.0 International License (https://creativecommons. org/licenses/by-nc/4.0/), which permits unrestricted use, distribution, and non-commercial reproduction in any medium, provided you give appropriate credit to the original author(s) and the source, provide a link to the Creative Commons license, and indicate if changes were made. The Creative Commons Public Domain Dedication waiver (http://creativecommons.org/publicdomain/zero/1.0/) applies to the data made available in this article, unless otherwise stated. 
works antagonistically to it. ${ }^{9}$ The key transcription factors involved in melanoblast migration are microphthalmia associated transcription factor (MITF), Sox 10, Pax 3 and FoxD3. ${ }^{10}$ Microphthalmia associated transcription factor is considered as the master regulator of melanocyte development, as they are responsible for differentiation, proliferation, and survival of MCs. They also activate other transcriptional and cell cycle progression genes necessary for the development of melanoblasts. Microphthalmia associated transcription factor mediates a-melanocyte stimulating hormone (a-MSH), a hormone responsible for production of melanin. ${ }^{11}$ The adhesion proteins are of particular importance as they migrate along the embryo to reach its final destination. Cadherins and integrins, along with other extracellular matrix elements, allow the melanoblasts to migrate through the extracellular matrix. ${ }^{8}$ Loss of any of the above mentioned factors during the specification of MC can result in the failure of its proper development.

Once the melanoblast cells have reached their final destination they differentiate into MC. Melanin production occurs in membranebound organelles called melanosomes. They are considered to be specialized lysosome-related organelles (Table 2). ${ }^{12,13}$ Melanosomes visualized under electron microscope traverse through four maturation stages. Stage I melanosomes/premelanosomes are small round structures. They are filled with amorphous matrix without any enzymes or pigments. All the enzymes necessary for melanin production start appearing in stage II. Melanosomes in this stage consist of more organized matrix, tyrosinase enzyme, and fibrillar protein. In stage III, melanin starts appearing, and the melanosomes acquire a more elliptical shape. Toward the final stage, stage IV, the entire melanosomes are packed with melanin granules. ${ }^{8}$

Melanogenesis is the process of melanin production by MCs. Melanogenesis requires many proteins, enzymes, and factors, all of which are present in the melanosomes. Chemically, melanin is a polymer based on tyrosine that is synthesized under the influence of enzymes such as tyrosinase, tyrosine-related protein 1, and $2 .{ }^{14}$ According to the pigment enzymes expressed, they can be divided into eumelanin and pheomelanin. Melanins differ in their structural, chemical, and physical properties, although they have a polymer chain of repeating carbon-carbon bonds. Eumelanin

Table 2: The origin and developmental stages of melanocytes

\begin{tabular}{|c|c|c|}
\hline $\begin{array}{l}\text { Phase of } \\
\text { development }\end{array}$ & Stage in fetal life & Features \\
\hline Origin & 9th-10th week & $\begin{array}{l}\text { Neural crest cells develop } \\
\text { into melanocyte precursor } \\
\text { cells called melanoblasts }\end{array}$ \\
\hline Migration & 10th-12th week & $\begin{array}{l}\text { Melanoblasts: their } \\
\text { migration from the neural } \\
\text { crest to peripheral sites }\end{array}$ \\
\hline Differentiation & 5th month & $\begin{array}{l}\text { Once they reach target sites, } \\
\text { melanoblasts differentiate } \\
\text { into melanocytes }\end{array}$ \\
\hline $\begin{array}{l}\text { Survival and } \\
\text { proliferation }\end{array}$ & 5th-6th month & $\begin{array}{l}\text { Decrease in the number } \\
\text { of dermal melanocytes, } \\
\text { Epidermal melanocytes } \\
\text { continue to proliferate and } \\
\text { start production of melanin }\end{array}$ \\
\hline $\begin{array}{l}\text { Melanin } \\
\text { production }\end{array}$ & $\begin{array}{l}\text { Evident from } \\
\text { 6th month onwards }\end{array}$ & $\begin{array}{l}\text { Established melanocytes } \\
\text { start producing } \\
\text { melanosomes }\end{array}$ \\
\hline
\end{tabular}

are brown-black large irregular granules, while pheomelanin are much smaller and regular yellow-red granules. A third category of melanin pigment known as neuromelanin is produced exclusively by the neurons of substantia nigra in the brain. All these types of melanins are capable of scavenging free radicals, thereby protecting human body from harmful effects. ${ }^{15}$

The melanins are transferred from mature melanocytes to surrounding keratinocytes via their dendritic process. With maturation and differentiation of oral epithelium, keratinocytes degrade and eventually release melanin to the surface as melanin dust that gets entangled in keratin filaments. ${ }^{10}$

Melanocytic stem cells reside in the bulge of hair follicles and are capable of self-renewal, whereas the niches for oral melanocytic stem cells remain unknown. ${ }^{16}$ However, the number of melanocytes present in the oral epithelium more or less remain in a steady state throughout life. ${ }^{10}$ With age, MCs become larger with more dendrites while the tyrosinase activity gets reduced. ${ }^{8}$

\section{Morphology of Melanocytes}

The information available about the morphology of OMMCs are more or less similar to epidermal melanocytes. In routine hematoxylin and eosin (H\&E)-stained sections, MCs are seen as small round or oval cells with clear cytoplasm placed immediately beneath the basal cell layer (Fig. 1). The clear cytoplasm is actually an artifact of fixation during which cytoplasm shrinks and becomes concentrated around the nucleus, thereby creating a lacuna. ${ }^{17}$ The nucleus is smaller and more hyperchromatic than the neighboring keratinocytes. The MCs consist of unipolar, bipolar, or multipolar dendrites that are invisible in $\mathrm{H} \& \mathrm{E}$-stained section unless they are packed with melanin granules. ${ }^{8}$

Under an electron microscope, melanocyte cytoplasm exhibits several well-developed organelles such as mitochondria, endoplasmic reticulum, and Golgi apparatus along with numerous melanosomes. The nucleus is smooth or lobated with uniform chromatin. The individual melanin granule has a size ranging from 0.1 to $0.4 \mu$ and is usually seen in the dendrites of the melanocytes. ${ }^{18}$

Routine H\&E-stained sections are not specific for visualizing MCs, and hence other histochemical techniques are required to

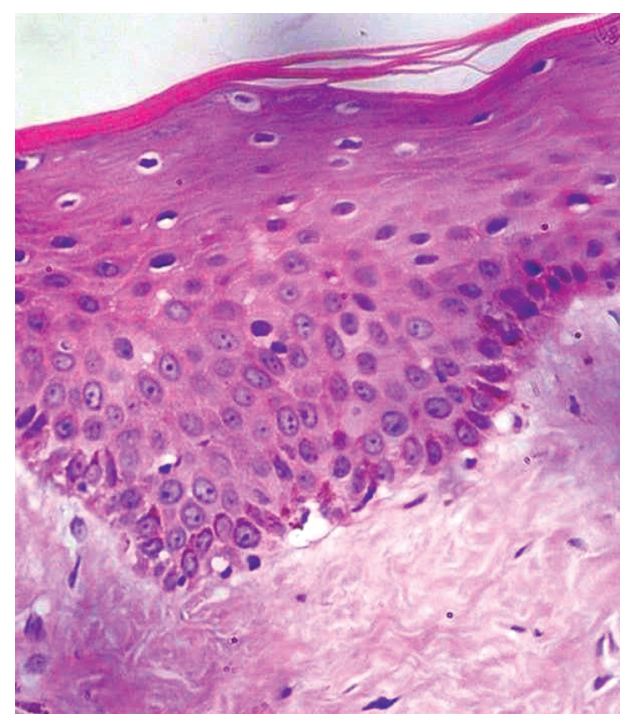

Fig. 1: Hematoxylin and eosin (H\&E)-stained sections of oral epithelium with melanin pigmentation in the basal layer (40× magnification) 
identify these cells. The commonly used technique is reducing silver stains such as Masson-Fontana and Schmorl's stain. The disadvantage of this technique is that other pigments like lipofuscin and hemoglobin also take up the stain and become difficult to distinguish. More specific methods include immunohistochemical markers such as HMB 45, Tyrosinase, Melan-A, Mitf, Sox 10, etc. Other identification processes include enzyme histochemistry using dopa oxidase technique, solubility, and bleaching methods using strong oxidizing agents and formalin-induced fluorescence. ${ }^{17}$

A morphological variant of MCs have been described called nevus cells. According to their morphology, nevus cells are again classified into Type A-epitheloid, Type B-lymphocytoid, and Type C - neuroid. They form nests of cells and can be seen in the epidermis, dermis, or in the dermoepidermal junction. ${ }^{18}$ They are also identified in the oral cavity and according to their location are classified as intramucosal, junctional, and compound nevi.

In oral cavity, melanocytes are most commonly seen in attached gingiva, buccal mucosa, palate, and tongue. ${ }^{5}$ In gingiva, melanin pigmentation is generally absent in free gingiva and mucogingival junction and gingival crevice. The pigmentation of human oral mucosa depends upon the amount of melanin, i.e., the maturation of melanosomes, the number of keratinocytes containing melanosomes, and the distribution of melanin loaded keratinocytes throughout the epithelium. ${ }^{19}$

\section{Melanocyte-Keratinocyte Unit}

The structural complex of both melanocytes and keratinocytes in the basal layer of the epithelium is called as "keratinocytemelanocyte unit" (Fig. 2). The ratio of MCs to keratinocytes ranges from 1:10 to $1: 15 .{ }^{10}$ The adhesion of MCs to keratinocytes is via tight junctions and gap junction, since they lack both desomsomes and tonofilaments. ${ }^{20}$ Adhesion molecules such as E- and P-cadherins participate in building cell-cell contact structures. ${ }^{21}$

Melanins produced within melanosomes are transferred to keratinocytes through the dendritic processes of MCs. One of the accepted mechanisms of melanin transfer is proposed by Ando et al. ${ }^{22} \mathrm{~A}$ membrane pigment globule is formed in MC which consists of melanosomes and few mitochondria. These pigment globules released by MCs into the extracellular space are captured by the microvilli of keratinocytes. In the keratinocytes, these are incorporated in a protease-activated receptor-dependent way, and finally the membrane surrounding the pigment globule degrades releasing melanin to the keratinocytes. These two cells coexist to maintain homeostasis. Keratinocytes have the ability to regulate melanogenesis via mediators such as a-MSH, adrenocorticotropin

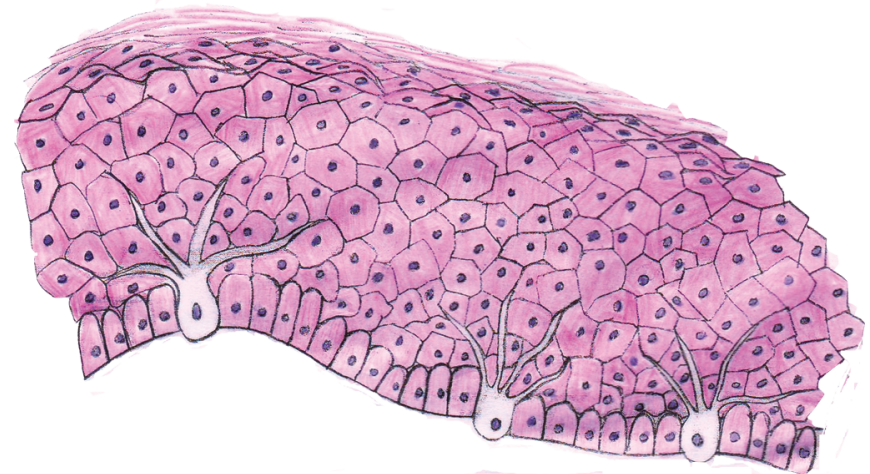

Fig. 2: Diagrammatic representation of oral epithelium with melanocytes in the basal layer hormone $(\mathrm{ACTH}), \beta$-endorphin, basic fibroblast growth factor (bFGF), endothelins, hepatocyte growth factor (HGF), and stem cell factor (SCF). ${ }^{23}$ Again, MCs through the chemical mediators in melanosomes can regulate the functional activities of keratinocytes. It has been reported that dermal fibroblasts also have a role in the development of melanocytes by secretion of factors such as stem cell factor (SCF) and neuregulin $1 .^{13}$

The cell turnover rate of keratinocytes is faster than that of melanocytes. Even after repeated exposure to UV rays, the MCs do not undergo apoptosis easily. The presence of antiapoptotic protein, bcl2, renders the MCs resistant to cell death as elucidated by Rinnerthaler et al. ${ }^{24}$ Therefore, longevity of MCs are associated with a risk of cumulative genetic damage. ${ }^{25}$

\section{Functions of OMMCs}

One of the basic functions of MC is the production of melanin pigment that aids in physiologic/racial pigmentation. The color of skin is not dependent on the number of melanocytes, as it is similar in individuals of all races. However, the capacity to produce melanin by these MCs varies among individuals. ${ }^{8}$ The large brown-black granules of eumelanin gives the skin a more darker shade, while the much smaller yellowish pheomelanin imparts lighter skin.

Apart from pigmentation of skin, melanins have much broader functions like photoprotection. The melanin pigment globules transferred to the keratinocytes reside in the nucleus of these cells forming "supranuclear caps" that protect the genetic material of epithelial cells from UV radiation. ${ }^{2}$

During melanogenesis and in response to UV radiation, a lot of free radicals such as hydroxyl ion, superoxide anion, nitric oxide, etc., are formed which are toxic and harmful to human body. Now, this is neutralized by various endogenous enzymatic and nonenzymatic antioxidants present in the MCs. Along with MCs, keratinocytes also produce melanocortin peptides, such as aMSH, which are capable of neutralizing the oxidative damage and thereby maintaining the homeostasis. $^{26}$

Melanocytes are often called as local stress sensors due to their simulation to a neuroendocrine cell. Melanocytes are closely associated with nerve endings, and they are also capable of producing neuropeptides and neurotransmitters. ${ }^{27}$ Therefore, MCs act as sensors between their habitat and central nervous system.

Oral mucosal melanins can act as a defense barrier by scavenging the free radicals and polycyclic compounds produced in response to gingival, periodontal, or other inflammatory conditions affecting the oral cavity. According to a study conducted by Nilima et al., ${ }^{28}$ inflammatory index was low in pigmented gingiva than nonpigmented gingival. Melanins present in the melanosomes are capable of neutralizing toxins and bacterial products, thereby creating an antimicrobial shield. Acid phosphatase, a-mannosidase, $\beta-\mathrm{N}$ acetyl glycosaminidase, and $\beta$-galactosidase are some of the lysosomal enzymes present in melanosomes which can degrade microorganisms. ${ }^{23}$ In addition to this, MCs are capable of producing a number of cytokines, including IL-1, IL 3, IL 6, and TNF-a, thereby acting as regulators of the immune system. ${ }^{29}$ 'Melanin dusts' left by the shedding keratinocytes are capable of rendering pathogens and toxins inactive.

The phagocytic activity and the production of various antiinflammatory and immunomodulatory substances point out that these dendritic cells have a role in antigen processing and presenting. Also, it is reported that Toll-like receptors and major histocompatibility complex class II molecules are expressed by 


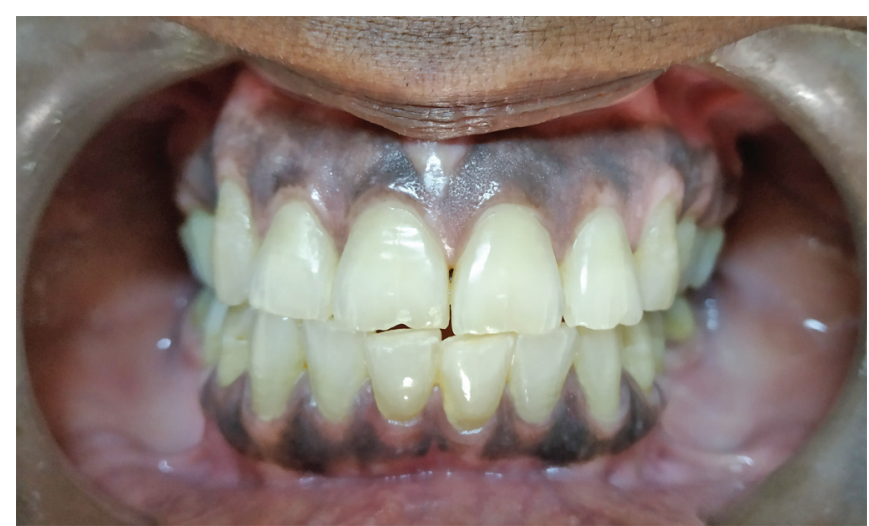

Fig. 3: Physiologic pigmentation seen on the labial-attached gingiva

normal human MCs. Therefore, MCs are capable of triggering several immune cells and can act as early sensors of immune system in the body. ${ }^{30}$

\section{Melanin Pigmentation in Oral Mucosa}

Oral mucosal pigmentation can be physiologic or pathologic. In oral cavity, physiologic pigmentation is present in almost all the soft tissues, but it is more commonly exhibited in gingiva (Fig. 3). As mentioned earlier, it is not the number of melanocytes that determines the skin color of an individual; rather, it is the number of melanosomes and the type of melanin secreted. Physiological pigmentation is common among darker skinned individuals, and it can range from light brown to almost black in color. Several factors such as smoking, hormones, and systemic medications can affect the color intensity of pigmentation. ${ }^{31}$

Pathologic pigmentation is associated with endocrine disorders, chronic irritation, reactive or neoplastic lesions, drugs, smoking or tobacco use, etc. ${ }^{32}$ Among these, long-term use of certain drugs such as nonsteroidal anti-inflammatory drugs, antimalarials, psychotropic drugs, tetracyclines, oral contraceptives etc., is one of the most common cause of oral and perioral pigmentation. ${ }^{33,34}$

\section{Recent Advances and Future Scopes}

An enormous data on the ontogeny of MCs have been unearthed, still many questions need answers. The neural crest origin of $\mathrm{MC}$ is an established fact, but this needs to be explored at the molecular level. A number of factors act together for the specification of MCs, but it is unknown as to how these factors coexist for the development of MCs.

Large number of studies are being held on MCs and the pathologic conditions caused by these cells. Yet another finding is the presence of fibronectin present in the extracellular vesicles released by the MCs. It was found that UVB radiation increases the production of extracellular vesicles by melanocytes. These fibronectin can bind with integrin receptors and aid in embryogenesis, tissue repair, and cancer. ${ }^{25}$

The niche for melanocyte stem cells resides in the hair follicle present in the skin. However, studies by Li et al., in human foreskin lacking hair follicles discovered that, when dermal stem cells are embedded into dermis, a subpopulation migrates to the basement membrane of the epidermis and differentiates into MCs. ${ }^{35}$ Thus, dermal stem cells might have the potential to replenish extra-follicular melanocytes. Again, the niche for human OMMCs has not been investigated, and therefore more studies need to be done in this field.

The extra pigmentary functions point out that MCs have a role as an accessory cell in immune system. Again, the physiological role of extracutanoeus MCs need to be explored. Do they have a similar function to epidermal melanocytes? Are they formed in a similar way from NCCs? This should be an area of interest to future researches, as there might lay the solutions for several of these unanswered questions regarding MCs and its functions.

\section{SUMmary}

Melanocytes are a heterogeneous group of cells due to their neural crest origin and varied distribution. Their basic function is considered to be the production of melanin pigment. However, a number of extra pigmentary functions such as, photoprotection, immunoregulation and modulation, scavenging of free radicals etc., have been elucidated. In oral cavity, MCs protect the oral mucosa from microorganisms, bacterial toxins, and other harmful substances through the scavenging property of melanin. Therefore, further research of these cells regarding its origin, development, and physiologic function could throw some light as to the exact role of these cells in the human body other than physiologic pigmentation.

\section{ACKnOWLedgments}

We would like to extend our gratitude to our lab technician Mrs Prathiba Basil and PG student Dr Sapna Chandran for helping us with Figure 1. The authors would also like to thank Mrs Lilly Stanley for her consent for Figure 3.

\section{References}

1. Westerhof W. The discovery of the human melanocyte. Pigment Cell Res 2006;19(3):183-193. DOI: 10.1111/j.1600-0749.2006.00313.x.

2. Brenner M, Hearing VJ. What are melanocytes really doing all day long...? From the view point of a keratinocyte: melanocytes-cells with a secret identity and incomparable abilities. Exp Dermatol 2009;18(9):799. DOI: 10.1111/j.1600-0625.2009.00912.x.

3. Laidlaw GF, Cahn LR. Melanoblasts in the gum. J Dent Res 1932;12:534537.

4. Becker SW, Zimmerman AA. Further studies on melanocytes and melanogenesis in the human fetus and newborn. J Invest Dermatol 1955;25(2):103-112. DOI: 10.1038/jid.1955.104.

5. Barrett AW, Scully C. Human oral mucosal melanocytes: a review. J Oral Pathol Med 1994;23(3):97-103. DOI: 10.1111/j.1600-0714.1994. tb01095.x.

6. Rawles ME. Origin of pigment cells from the neural crest in the mouse embryo. Physiol Zool 1947;20(3):248-266. DOI: 10.1086/ physzool.20.3.30151958.

7. Rawles ME. Origin of melanophores and their role in development of color patterns in vertebrates. Physiol Rev 1948;28(4):383-408. DOI: 10.1152/physrev.1948.28.4.383.

8. Cichorek M, Wachulska M, Stasiewicz A, et al. Skin melanocytes: biology and development. Postepy Dermatol Alergol 2013;30(1):3041. DOI: $10.5114 /$ pdia.2013.33376.

9. Thomas AJ, Erickson CA. The making of a melanocyte: the specification of melanoblasts from the neural crest. Pigment Cell Melanoma Res 2008;21(6):598-610. DOI: 10.1111/j.1755-148X.2008.00506.x.

10. Feller L, Masilana A, Khammissa RA, et al. Melanin: the biophysiology of oral melanocytes and physiological oral pigmentation. Head Face Med 2014;10:8. DOI: 10.1186/1746-160X-10-8. 
11. Levy C, Khaled M, Fisher DE. MITF: master regulator of melanocyte development and melanoma oncogene. Trends Mol Med 2006;12(9):406-414. DOI: 10.1016/j.molmed.2006.07.008.

12. Orlow SJ. Melanosomes are specialized members of the lysosomal lineage of organelles. J Invest Dermatol 1995;105(1):3-7. DOI: 10.1111/1523-1747.ep12312291.

13. Gertrude EC, Vincent JH. Human skin pigmentation: melanocytes modulate skin color in response to stress. FASEB J 2007;21(4):976-994. DOI: 10.1096/fi.06-6649rev.

14. Lin JY, Fisher DE. Melanocyte biology and skin pigmentation. Nature 2007;445(7130):843-850. DOI: 10.1038/nature05660.

15. Prota G. Melanins and Melanogenesis. London: Academic Press; 2012. pp. 1-13.

16. Nishimura EK, Jordan $\mathrm{SA}$, Oshima $\mathrm{H}$, et al. Dominant role of the niche in melanocyte stem-cell fate determination. Nature 2002;416(6883):854-860. DOI: 10.1038/416854a.

17. Bancroft J, Gamble M. Theory and Practice of Histological Techniques. 5th ed., New York: Churchill Livingstone; 2002. pp. 240-245.

18. Busam KJ, Barnhill RL, Piepkorn MW. Melanocytes. In: Barnhill RL, Piepkorn MW, Busam KJ. Pathology of Melanocytic Nevi and Melanoma. Berlin Heidelberg: Springer; 2014. pp.1-11.

19. Moneim RA, El Deeb M, Rabea AA. Gingival pigmentation cause, treatment and histological preview. Future Dental Journal 2017;3(1): 1-7. DOI: 10.1016/j.fdj.2017.04.002.

20. Nordlund JJ. The melanocyte and the epidermal melanin unit: an expanded concept. Dermatol Clin 2007;25(3):271-281. DOI: 10.1016/j. det.2007.04.001.

21. Haass NK, Smalley KS, Li L, et al. Adhesion, migration and communications in melanocytes and melanoma. Pigment Cell Res 2005;18(3):150-159. DOI: 10.1111/j.1600-0749.2005.00235.x.

22. Ando $H$, Niki $Y$, Ito $M$, et al. Melanosomes are transferred from melanocytes to keratinocytes through the processes of packaging, release, uptake, and dispersion. J Investig Dermatol 2012;132(4): 1222-1229. DOI: 10.1038/jid.2011.413.

23. Hirobe T. Role of keratinocyte-derived factors involved in regulating the proliferation and differentiation of mammalian epidermal melanocytes. Pigment Cell Res 2005;18(1):2-12. DOI: 10.1111/j.16000749.2004.00198.x.

24. Rinnerthaler $M$, Streubel $M K$, Bischof J, et al. Skin aging, gene expression and calcium. Exp Gerontol 2015;68:59-65. DOI: 10.1016/ j.exger.2014.09.015.

25. Bin BH, Kim DK, Kim NH, et al. Fibronectin containing extracellular vesicles protect melanocytes against ultraviolet radiation-induced cytotoxicity. J Invest Dermatol 2016;136(5):957-966. DOI: 10.1016/ j.jid.2015.08.001.

26. Tsatmali M, Ancans J, Thody AJ. Melanocyte function and its control by melanocortin peptides. J Histochem Cytochem 2002;50(2): 125-133. DOI: 10.1177/002215540205000201.

27. Slominski A, Paus R, Schadendorf D. Melanocytes as "sensory" and regulatory cells in the epidermis. J Theor Biol 1993;164(1):103-120. DOI: 10.1006/jtbi.1993.1142.

28. Nilima $S$, Vandana KL. Melanin: a scavenger in gingival inflammation Indian J Dent Res 2011;22(1):38-43. DOI: 10.4103/0970-9290.79973.

29. LuY,ZhuWY, Tan C, etal.Melanocytes are potential immunocompetent cells: evidence from recognition of immunological characteristics of cultured human melanocytes. Pigment Cell Res 2002;15(6):54-460. DOI: $10.1034 /$ j.1600-0749.2002.02065.x.

30. Hong Y, Song B, Chen HD, et al. Melanocytes and skin immunity. J Invest dermatol Symp Proc 2015;17(1):37-39. DOI: 10.1038/ jidsymp.2015.14.

31. Eisen D. Disorders of pigmentation in the oral cavity. Clin Dermatol 2000;18(5):579-587. DOI: 10.1016/s0738-081x(00)00148-6.

32. Sreeja C, Ramakrishnan K, Vijayalakshmi D, et al. Oral pigmentation: a review. J Pharm Bioallied Sci 2015;7(Suppl 2):S403. DOI: 10.4103/09757406.163471.

33. Dereure O. Drug-induced skin pigmentation. Am J Clin Dermatol 2001;2(4):253-262. DOI: 10.2165/00128071-200102040-00006.

34. Abdollahi M, Radfar M. A review of drug-induced oral reactions. J Contemp Dent Pract 2003;4(1):10-31. DOI: 10.5005/jcdp-4-1-10.

35. Li L, Fukunaga-Kalabis $\mathrm{M}, \mathrm{Yu} \mathrm{H}$, et al. Human dermal stem cells differentiate into functional epidermal melanocytes. J Cell Sci 2010;123(Pt 6):853-860. DOI: 10.1242/jcs.061598. 